\title{
Three-Point Bending Test for Three Different Bolt Diameters
}

\author{
* Nor Jihan Abd Malek, Sadiq Azizi Othman \\ Centre of Geo-hazards in Structures, Reliability Management \& Material, \\ Faculty of Engineering \& Built Environment, SEGi University
}

*jihanabdmalek@segi.edu.my

\begin{abstract}
Timber is one of the oldest materials used as main structural element prior concrete and steel which have greater ability to sustain load. The greater demand for timber as construction materials, the wood engineering introduced a new timber type called Engineered Wood Product (EWP). The crucial problem in the timber structure which focuses on the structural timber connection. The load-carrying capacity of the timber connection and the failure modes can be determined according to the European Yield Model (EYM). Three-point bending test was used to determine yield moment of the fastener, $\mathrm{M}_{\mathrm{y}}$, bolt bending strength, $\mathrm{F}_{\mathrm{yb}}$ and average R-value for three selected different bolt diameters which are 12,16 and $20 \mathrm{~mm}$. The results were obtained for comparing between three bolt diameters with $\mathrm{F}_{2 \%}, \mathrm{~F}_{5 \%}$ and $\mathrm{F}_{\max }$ respectively. The $\mathrm{F}_{2}$ for 12,16 and $20 \mathrm{~mm}$ yield moment of the fastener, $\mathrm{M}_{\mathrm{y}}$ was obtained 596.4, 1631.5 and $4650 \mathrm{kNmm}$ accordingly while for bolt bending strength, $\mathrm{F}_{\mathrm{yb}}$ was $2.1,2.4$ and $3.5 \mathrm{kN}$ correspondingly. The $\mathrm{F}_{5 \%}$ for 12 , 16 and $20 \mathrm{~mm}$ yield moment of the fastener, $\mathrm{M}_{\mathrm{y}}$ was obtained 631.1, 1668.3 and $4895.6 \mathrm{kNmm}$ accordingly while for bolt bending strength, $\mathrm{F}_{\mathrm{yb}}$ was 2.2, 2.4 and $3.7 \mathrm{kN}$ correspondingly. The $\mathrm{F}_{\max }$ for 12,16 and $20 \mathrm{~mm}$ yield moment of the fastener, $\mathrm{M}_{\mathrm{y}}$ was obtained 828.2, 2290.8 and $6545.4 \mathrm{kNmm}$ accordingly while for bolt bending strength, $\mathrm{F}_{\mathrm{yb}}$ was $2.9,3.4$ and $4.9 \mathrm{kN}$ correspondingly. The average R-value for 12,16 and $20 \mathrm{~mm}$ bolt diameter was 0.50214 , 0.42768 and 0.42038 individually. In conclusion, the percentage difference for $\mathrm{F}_{2 \%}$ bolt bending strength, $\mathrm{F}_{\mathrm{yb}}$ between 12 and $16 \mathrm{~mm}$ has raised about $14 \%$ whereas 16 and $20 \mathrm{~mm}$ has shown $46 \%$ increased.
\end{abstract}


Keywords: Engineered Wood Product, European Yield Model, three-point bending test, yield moment, bolt bending strength

\section{Introduction}

Beginning with an examination of the microstructure of wood, the properties of wood and the elements that impact them are expounded. The execution of auxiliary timber is affected by the essential wood properties, for example, ties. The impact of these imperfections on the auxiliary properties is inspected. Testing and evaluating is utilized to characterize timber into various evaluations or quality classes to fulfil diverse end client prerequisites and guarantee item dependability. Strategies for testing and evaluating are portrayed together with methods for deciding trademark esteems for configuration purposes. At last, the natural effect of timber development is considered (Zylkowski, 2002). An assortment of commonly used techniques are known to connect timber to timber or steel to timber and bolt joint is viewed as one of them. Design codes in timber and utilizing on the European Yield Models (EYM), the followed equations anticipates the timber connections ability and on the off chance that it has a lateral load dowel fastener. Two models shapes the primary guideline of the EYM (the procedure of wood levelling beneath fasteners and the production of plastic joints in fasteners utilizing hard plastic among the utilized substances) (Baxter et al., 2008). Thus, the research was focuses on the comparison between bolt bending strength, $\mathrm{F}_{\mathrm{yb}}$ and $\mathrm{F}_{2 \%}, \mathrm{~F}_{5 \%}, \mathrm{~F}_{\max }$ respectively. It also compared for $\mathrm{F}_{2 \%}$ of bolt bending strength, $F_{y b}$ percentage difference between 12 and $16 \mathrm{~mm}$ also 16 and $20 \mathrm{~mm}$ bolt diameters.

\section{Literature Review}

Pirvu, et al (2000) has made the study of wood structures in Japan seem to be able to withstand seismic disturbance and have good performance and stability during the event, particularly some of the classical structures like pagodas. Albright (2006) specified that the connection is particularly inspired by stability in the design of wood structures. Larsen (1973) specified that the connection during timber structural design is the most important part of the 
system. It also transfers the members load and provides ductility within the structural system to the members.

Figure 1 shows bolt and nut configuration which consist of head, shank, thread, washer and nut. The bearing that originates to the bolts then into timber can allocate a great source of information about the bolt strength. The physical and geometric characteristics depend together with timber members on the stiffness and strength of the single bolt connection. The characteristics of the bolt can be demonstrated by its diameter and the bolt yield strength. Geometric aspects consist of fabrication of bolt hole, end or edge distance and spacing (Soltis \& Wilkinson, 1987).

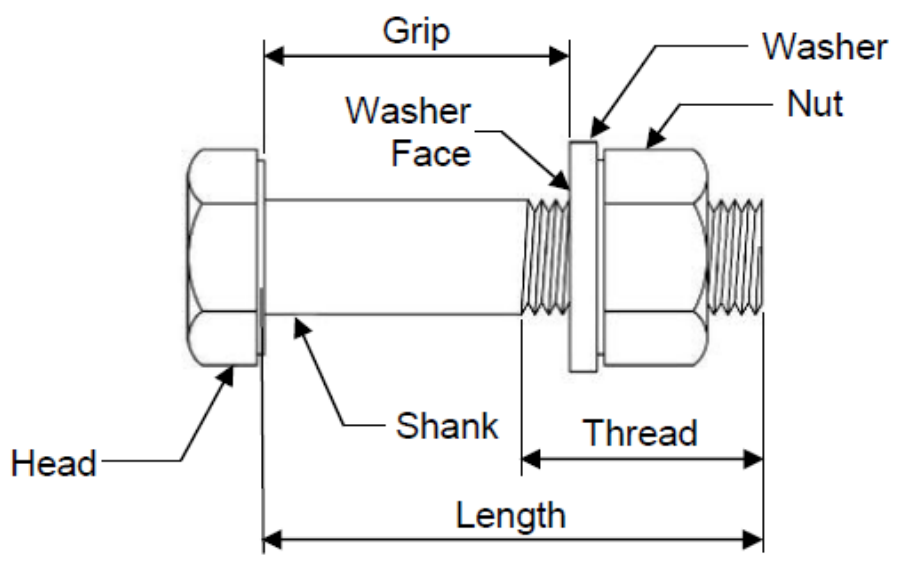

Figure 1. Bolt and nut configuration (Carter, 1996)

Splitting under the bolt is the main reason some bolted connection goes wrong. If the bolt tends to wedge through the timber triggered by tension that is perpendicular to grain pressures, this way of connection. This kind of failure can be fixed by enhancing reliability and capacity bolt connection. Total solidity of the timber structure therefore needs to be improved by applying powerful materials in the engineering industry (Soltis et.al, 1986). Figure 2 shows the typical load deformation curve of $\mathrm{F}_{5 \%}$ offset load. Figure 3 shows modes of failure for double shear timber and panel connection notation as $\mathrm{g}$ which the failure modes occurred on the side member, $h$ representing the failure happened in the main member, $\mathrm{j}$ denoted dowel yield occured in main member and $\mathrm{k}$ characterized yield happened in both main and side member. 


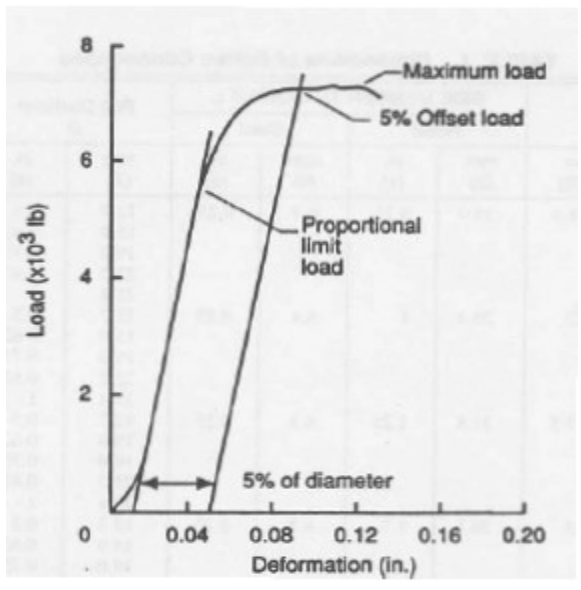

Figure 2. Typical oad-deformation curve (ASTM D 5764, 2007)

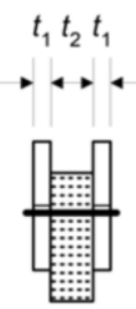

g

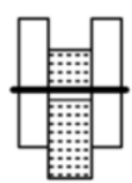

h

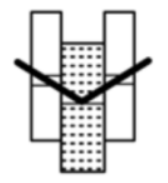

j

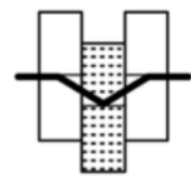

k

Figure 3. Modes of failure for timber and panel connections (Eurocode 5, 2008)

\section{Materials and Methods}

The main objective of this study is to determine bolt bending strength of $12 \mathrm{~mm}, 16 \mathrm{~mm}$ and $20 \mathrm{~mm}$ diameter. The laboratory test was performed using a three-point bending test method. Albright (2006) determined the characteristic of the yield bending of the fastener using three-point bending test and the other one is the cantilever test method. In this study, the threepoint bending test is selected because of the laboratory's limited availability device and equipment. There are 15 samples of bolt has been tested and Table 1 shows the properties of bolt. 
Table 1. Properties of bolt

\begin{tabular}{|l|c|c|c|}
\hline \multicolumn{1}{|c|}{ Properties } & \multicolumn{3}{|c|}{ Remarks } \\
\hline The diameter of the bolt, $d, \mathrm{~mm}$ & 12 & 16 & 20 \\
\hline Minimal thickness of the single washer, $0.3 d, \mathrm{~mm}$ & 4 & 5.3 & 6.7 \\
\hline Nominal thickness of the nut, $0.8 d \mathrm{~mm}$ & 9.6 & 12.8 & 16 \\
\hline Thickness of timber to steel plates structure, $\mathrm{t}, \mathrm{mm}$ & 120 & 120 & 120 \\
\hline $\begin{array}{l}\text { Threaded length of the bolt, } b \mathrm{~mm}(\text { not included in } \\
\text { determined the total length of bolt) }\end{array}$ & 30 & 38 & 52 \\
\hline $\begin{array}{l}\text { Minimal total length of the bolt plus with } 2 \% \text { extra } \\
\text { length, mm }\end{array}$ & 145.6 & 154.1 & 162.7 \\
\hline
\end{tabular}

The equipment set up follows the American Standard Test Method (ASTM D 5764, 2007), since Eurocode's standard practice is only available in designing the structure of the timber. Eurocode's standard practice for testing the bending of the fastener was not yet available, the ASTM F1575: Standard Test Method for Determining the Bending Yield Moment of Nails was used as a guideline in this study with some modification to the test set up to meet the standard. Figure 4 shows the schematic diagram of the set up length required followed the ASTM F 1575-03. Albright (2006) modified setting up the device and applying the modification from his previous study.

Meanwhile, the second objective of this study, which is to compare between the three selected diameters of the bolts bolt bending strength, $\mathrm{F}_{\mathrm{yb}}$ and $\mathrm{F}_{2 \%}, \mathrm{~F}_{5 \%}, \mathrm{~F}_{\max }$ respectively. This comparison is to determine whether its performance is simply proportional to the sizes of the diameters. The hypothesis assumed for this research is that the strength of the bolt will be increased proportionately with an increased in diameter sizes used. Figure 5 shows the configuration of three-point bending test for bolt which was done in the lab. 


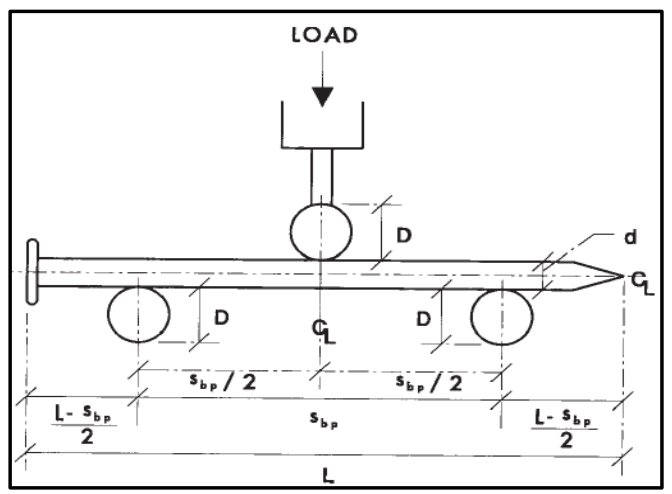

Figure 4. Schematic of the set up length required (ASTM F1575, 2003)

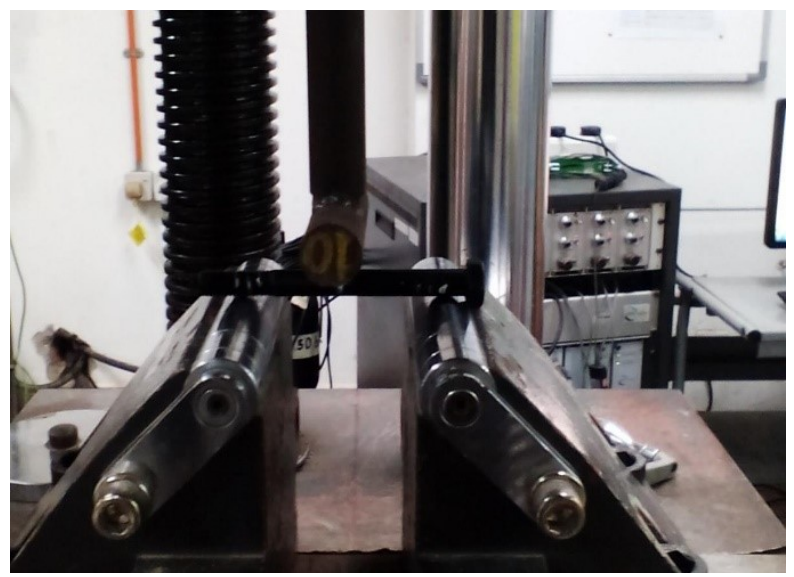

Figure 5. Configuration of three-point bending test

\section{Result and Discussion}

The three-point bending test was conducted to analyse the properties of the bolt by the maximum stress, two percent $(2 \%)$, five percent $(5 \%)$ of yield moment, and R-value graph to determine the mechanical properties of the bolts. The plotted graph of the stress-strain graph can determine all of these results. According to Pytel and Kiusalaas (2011) the temperature in causes dimensional changes a body resulting in expansion, whereas a decrease in temperature produces contraction within the material.

The maximum stress value obtained from the stress-strain graph is the maximum stress or much to be known as the Ultimate Tensile Stress (UTS). 
This is the maximum stress the bolt can withstand before failing or breaking while being stretched or pulled. Yield point is the point at which the stressstrain diagram begins to change its behaviour or permanently deform from a linear increase as the load applied earlier. The yield points resulting from this study came from a $2 \%$ offset at the axis of the strain $(\varepsilon=0.002)$. This yield point was determined from the $2 \%$ offset line intersection parallel to the line where the curve is most likely to increase linearly or, in other words, the initial tangent curve before it begins to change.

The concept of yield point for $5 \%$ offset is the same as the $2 \%$ offset as discussed before. The difference is just the parallel line of the tangent line starting at $5 \%(\varepsilon=0.005)$. The reason for getting the yield point result at an offset of 5\% is because some structure design uses a $5 \%$ offset value based on the standards used. To make the result obtained more flexible with other design standards, this study provided some results that were mostly practiced in the design of world standards. R-squared for linear regression models is a goodness-of-fit measure. This statistic shows the percentage of variance that the independent variables collectively explain in the dependent variable. Rsquared measures on a convenient scale of $0-100$ percent the strength of the relationship for both the model and the dependent variable. Calculated moment, $M_{y}$ is the moment obtained from the formula $\mathrm{S}_{\mathrm{bp}} / 2$ where $\mathrm{S}_{\mathrm{bp}}$ equals to the cylindrical bearing point spacing, $\mathrm{mm}$ as shown in Equation 1, Equation 2 and Equation 3.

$$
\begin{array}{ll}
M_{y}=F_{2 \%} \times \frac{s_{b p}}{2} & \text { Eq. } 1 \\
M_{y}=F_{5 \%} \times \frac{s_{b p}}{2} & \text { Eq. } 2 \\
M_{y}=F_{\text {max }} \times \frac{s_{b p}}{2} & \text { Eq. } 3
\end{array}
$$

where $\mathrm{S}_{\mathrm{bp}}$ is equal to the cylindrical bearing point spacing, $\mathrm{mm}$

The bolt's mechanical properties are likely to follow steel's properties as bolt is made of steel. Stress is the load applied over the specimen's crosssectional area, assuming that the stress is constant over the cross-sectional 
length (Hibbler, 2014). In simplified equation, this expression can be shown in Equation 4.

$$
\sigma=\frac{P}{A} \quad \text { Eq. } 4
$$

where,

$$
\begin{array}{ll}
\sigma & \text { stress } \\
\mathrm{P} & \text { applied load }
\end{array}
$$

A cross sectional area

Furthermore, for the bolt bending strength, $\mathrm{F}_{\mathrm{yb}}$ the formula is shown in Equation 5 and Equation 6.

$$
\begin{array}{ll}
F_{y b}=\frac{M_{y}}{S} & \text { Eq. } 5 \\
S=\frac{D^{3}}{6} & \text { Eq. } 6
\end{array}
$$

$\mathrm{D}=$ diameter of the bolt

The mean yield of $2 \%$ of the $12 \mathrm{~mm}, 16 \mathrm{~mm}$ and $20 \mathrm{~mm}$ size of bolts are $8.7 \mathrm{kN}, 17.7 \mathrm{kN}$ and $40.4 \mathrm{kN}$ respectively. The results pattern still shows that the $20 \mathrm{~mm}$ has the highest yield point while the mean yield point for the 12 $\mathrm{mm}$ diameter is the lowest compared to all three sizes. As declared earlier, the pattern of the result obtained might be influenced largely with the length of the bolt itself. This shown that, the $20 \mathrm{~mm}$ diameter still can withstand the largest stress before it begins to deform at this point. Figure 6 shows the Rvalue graph for $12 \mathrm{~mm}$ of $\mathrm{F}_{2 \%}$. The graph shows the linear proportional line and it can be seen that the value of $\mathrm{R}$ obtained was 0.13921 . Figure 7 shows the $\mathrm{R}$-value graph for $12 \mathrm{~mm}$ of $\mathrm{F}_{5 \%}$ and the linear proportional line. It can be seen that the value of $\mathrm{R}$ obtained was 0.18992 . Figure 8 shows the $\mathrm{R}$-value graph for $12 \mathrm{~mm}$ of $F_{\max }$. It can be seen that the value of $\mathrm{R}$ obtained is 0.25004 . The graph shows the linear proportional line. The line of the graph looks fit quite perfectly into the graph. 


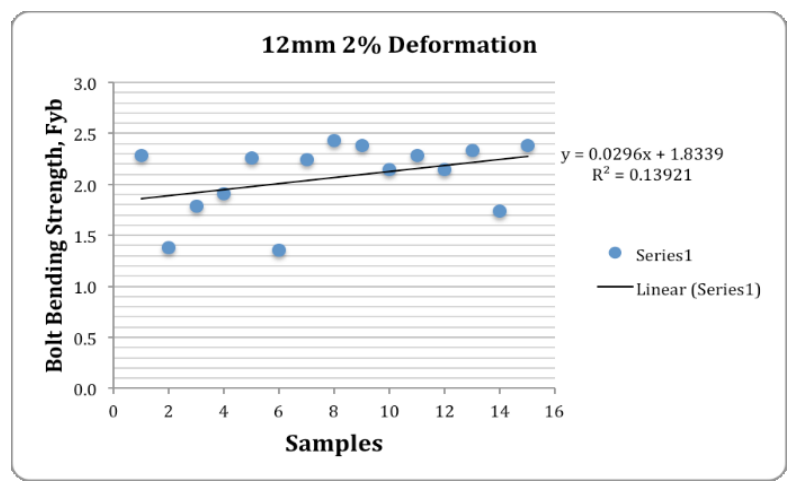

Figure 6. R-value for $12 \mathrm{~mm} 2 \%$ deformation

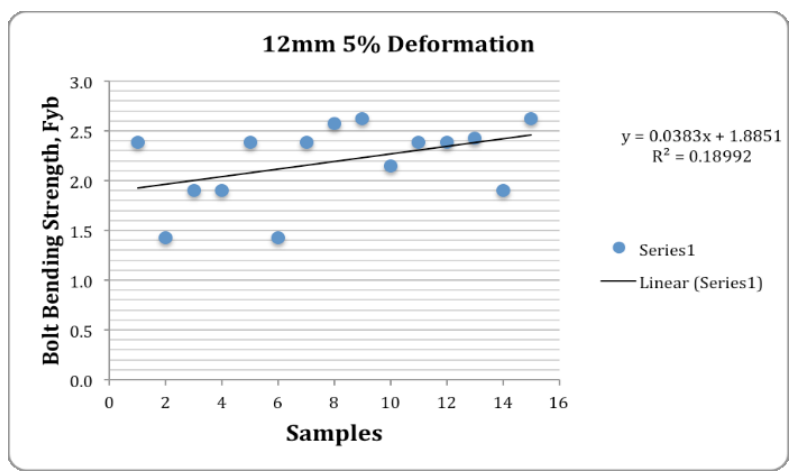

Figure 7. R-value for $12 \mathrm{~mm} \mathrm{5 \%}$ deformation

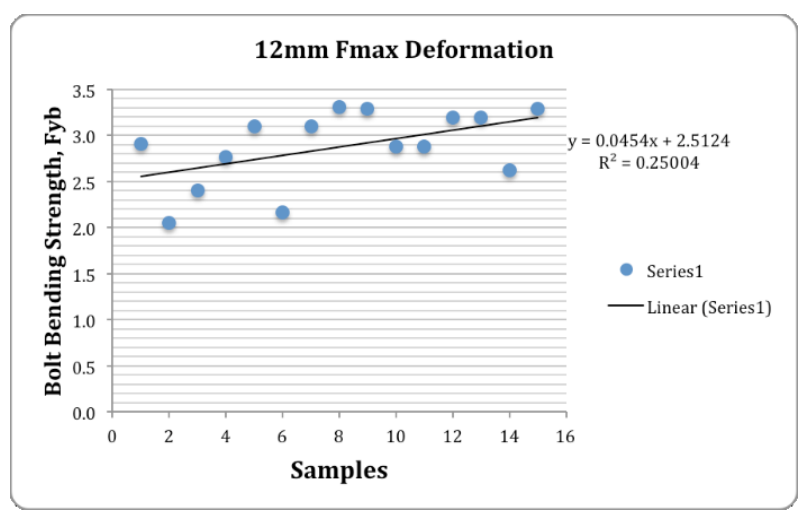

Figure 8. R-value for $12 \mathrm{~mm} \mathrm{~F}_{\max }$ deformation 


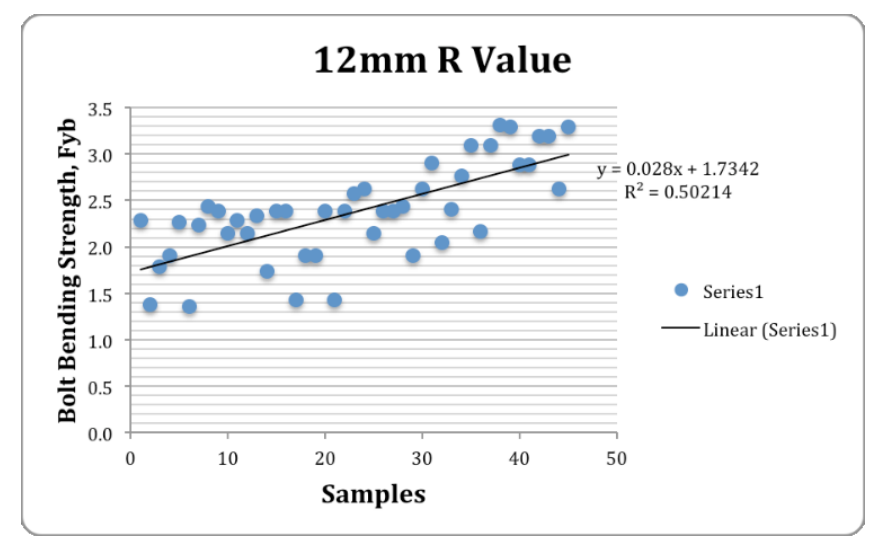

Figure 9. R-value for overall $12 \mathrm{~mm}$ deformation

Figure 9 shows the R-value graph for overall $12 \mathrm{~mm}$ deformation. It can be seen that the value of $\mathrm{R}$ obtained was 0.50214 . The graph shows the linear proportional line. The linear line was acceptable for the average total of 45 data. It shown that the value that proved the research hypothesis. Hwang and Komatsu, 2002 demonstrated that regression coefficient, R-value shown lower value due to variety behaviour of the timber species and bolt size diameter.

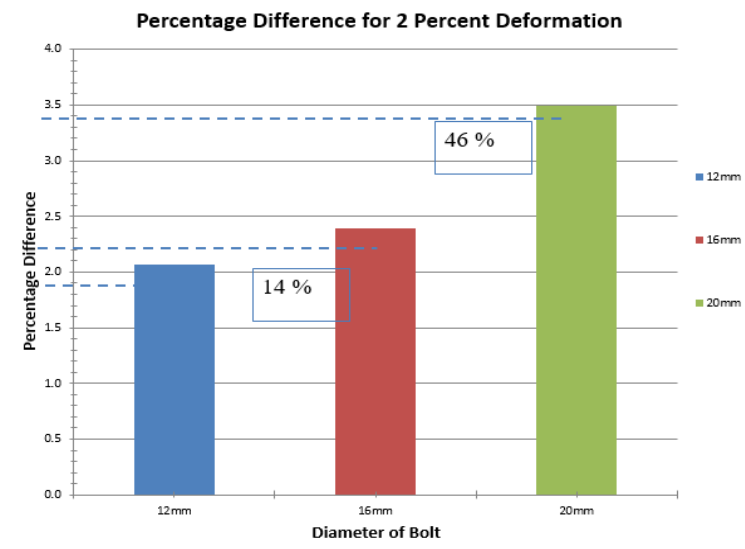

Figure 10. Percentage difference of 12,16 and $20 \mathrm{~mm}$ diameter of bolt

Figure 10 shows the percentage difference of 12, 16 and $20 \mathrm{~mm}$ diameter of bolt. The percentage difference obtained between $12 \mathrm{~mm}$ and $16 \mathrm{~mm}$ 
diameter of bolt is $14 \%$ whereas the percentage difference obtained between $16 \mathrm{~mm}$ and $20 \mathrm{~mm}$ diameter of bolt is $46 \%$. Figure 11 shows the bolt yield under mode of failures of timber or panel connection.

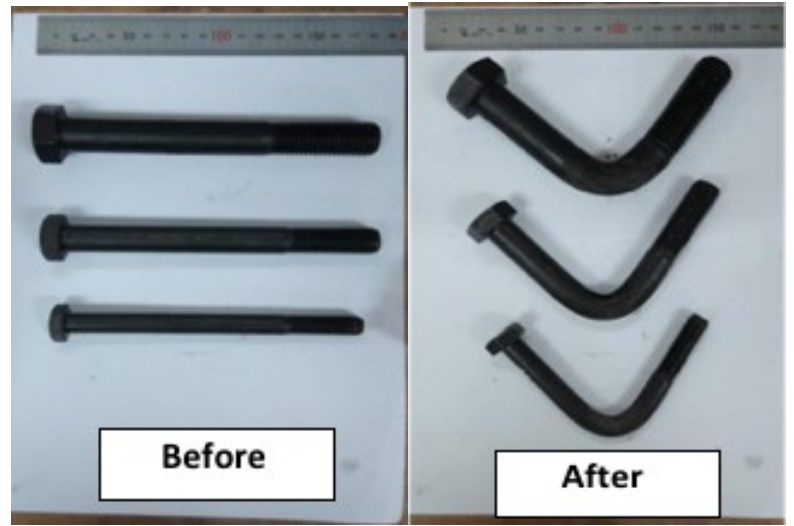

Figure 11. The bolts (a) before and (b) after the test done

\section{Conclusion}

The mean value of the maximum stress for the bolt size 12,16 and $20 \mathrm{~mm}$ are $12.1 \mathrm{kN}, 24.9 \mathrm{kN}$ and $56.9 \mathrm{kN}$ respectively. Meanwhile the mean of bolts of size 12,16 and $20 \mathrm{~mm}$ for $2 \%$ offset of yield stress are $8.7 \mathrm{kN}, 17.7 \mathrm{kN}$ and $40.4 \mathrm{kN}$ respectively. Moreover, for the $5 \%$ offset of yield stress are $9.2 \mathrm{kN}$, $18.1 \mathrm{kN}$ and $42.5 \mathrm{kN}$ respectively. The bolt $20 \mathrm{~mm}$ was the highest in bending yield strength compared to $12 \mathrm{~mm}$ and $16 \mathrm{~mm}$ because the bolt diameter was affected when finding the yield strength of the bolts. The bigger the diameter, the more bolt can sustain the load of bolt bending.

\section{Acknowledgement}

The authors would like to thank SEGi University for all the supports and UiTM laboratory for assisting the experimental works.

\section{References}

Albright, D. G. (2006). "The effects of bolt spacing on the performance of single-shear timber connections under reverse-cyclic loading " (Doctoral dissertation, Virginia Tech). 
American Society for Testing and Materials (2007). "Standard Test Method for Evaluating Dowel-Bearing Strength of Wood and Wood-Based Products." American Society of Testing and Materials Designation D 5764-97.

American Society for Testing and Materials (2003). "Standard Test Method for Determining Bending Yield Moment of Nails." American Society of Testing and Materials Standard F 1575-01. ASTM, Philadelphia, PA.

American Society for Testing and Materials (2007a). "Standard test method for determining bending yield moment of nails." F1575, West Conshohocken, PA.

Baxter, R., Hastings, N., Law, A., and Glass, E. J. (2008). Understanding Wood. Animal Genetics (Vol. 39).

Carter, C.J., 1996, "Specifying Bolt Length for High Strength Bolts," Engineering Journal, Vol. 33, No. 2, (2 ${ }^{\text {nd }}$ Qtr.), AISC, Chicago, IL.

EN 1995-1-1 (2008) (English): Eurocode 5: Design of timber structures - Part 1-1: General - Common rules and rules for buildings.

Hibbeler, R. (2014). Mechanics of Materials. 9th ed. Boston: Pearson Prentice Hall.

Hwang, K., and Komatsu, K. (2002). Bearing properties of engineered wood products I: effects of dowel diameter and loading direction. Journal of wood science, 48(4), 295-301.

Larsen, H. J. (1973). “The yield of bolted and nailed joints.” Proc., Div. V Conf., Int. Union of Forestry Res. Org., 646-654.

Pirvu, C., Yoshida, H., Inayama, M., Yasumura, M., and Taki, K. (1999). Development of LVL frame structures using glued metal plate joints II : strength properties and failure behaviour under lateral loading. Wood Sci , 193-201. 
Pytel A. and Kiusalaas J. (2011). Mechanics of Material (2ed.,CL,2011)(ISBN 0495667757)(576s) EM.

Soltis, L. A., and Wilkinson, T. L. (1987). "Bolted-connection design," Gen. Tech. Rep. FPL-GTR-54, U.S. Department of Agriculture, Forest Service, Forest Products Laboratory, Madison, Wisc.

Soltis, L. A., Hubbard, F. K., and Wilkinson, T. L. (1986). "Bearing strength of bolted timber joints.” J. Struct. Engrg., ASCE, 112(9), 2141-2154. Timber construction manual. (1985). 3rd Ed., American Institute of Timber Construction, Englewood, Colo.

Thelandersson, S. (2003). Introduction: Wood as a Construction Material. In S.Thelandersson, \& H. J. Larsen, Timber Engineering (pp. 15-22). England: John Wily \& Sons Ltd.

Zylkowski, S. (2002). Introduction to wood as an engineering material. APA Engineered Wood Handbook, (January 2009), 1.1-1.25 https://doi.org/10.1680/mocm.00000.0001 